\title{
IL-12p70-producing patient DC vaccine elicits Tc1-polarized immunity
}

Beatriz M. Carreno,, Michelle Becker-Hapak, ${ }^{1}$ Alexander Huang, ${ }^{1}$ Megan Chan, ${ }^{1}$ Amer Alyasiry, ${ }^{1}$ Wen-Rong Lie, ${ }^{2}$ Rebecca L. Aft, ${ }^{3}$ Lynn A. Cornelius, ${ }^{4}$ Kathryn M. Trinkaus, ${ }^{5}$ and Gerald P. Linette ${ }^{1}$

1Department of Medicine, Division of Oncology, Washington University School of Medicine, St. Louis, Missouri, USA.

2EMD Millipore, St. Charles, Missouri, USA. ${ }^{3}$ Department of Surgery, ${ }^{4}$ Department of Medicine, Division of Dermatology, and ${ }^{5}$ Division of Biostatistics, Washington University School of Medicine, St. Louis, Missouri, USA.

Background. Systemic administration of IL-12p70 has demonstrated clinical activity in cancer patients, but doselimiting toxicities have hindered its incorporation in vaccine formulations. Here, we report on the immunological and clinical outcomes upon vaccination with CD40L/IFN- $\gamma$-matured, IL-12p70-producing DCs.

Methods. 7 HLA-A*0201+ newly diagnosed stage IV melanoma patients were immunized against the gp100 melanoma antigen using autologous peptide-pulsed, CD40L/IFN- $\gamma$-matured DCs. PBMCs were taken weekly for immune monitoring by tetramer analysis and functional assays. CT imaging was performed at baseline, week 9 , and week 18 for clinical assessment using RECIST.

Results. 6 of 7 treated patients developed sustained T cell immunity to all 3 melanoma gp100 antigen-derived peptides. 3 of the 6 immunological responders developed confirmed clinical responses $(1$ complete remission $>4$ years, 2 partial response). Importantly, DC vaccine-derived IL-12p70 levels positively correlated with time to progression $(P=0.019$, log-rank), as did T-cytotoxic 1 (Tc1) immunity, as assessed by IFN- $\gamma / \mathrm{IL}-13$ and IFN- $\gamma / \mathrm{IL}-5$ ratios $(P=0.035$ and $P=0.030$, respectively, log-rank). In contrast, a pathway-specific defect in IL-12p35 transcription was identified upon CD40L/IFN- $\gamma$ activation in clinical nonresponder patient DCs, and gp100-specific $T$ cells from these patients displayed a Tc2 phenotype. Incorporation of TLR3 and TLR8 agonists into the CD40L/IFN- $\gamma$ activation protocol corrected the IL-12p70 production defect in DCs derived from clinical nonresponder patients.

Conclusion. These findings underscore the essential role of IL-12p70 in the development of therapeutic type 1 antigen-specific $\mathrm{CD8}^{+} \mathrm{T}$ cell immunity in humans with cancer.

Trial registration. Clinicaltrials.gov NCT00683670.

Funding. Barnes-Jewish Hospital Foundation, Siteman Cancer Frontier Fund, Washington University/JNJ Translational Medicine Award, and NCI (P30 CA91842).

\section{Introduction}

DCs are widely regarded as the most potent antigen-presenting cells to initiate $\mathrm{T}$ cell immunity. Although immature DCs (iDCs) can process and present antigens, these cells fail to produce proinflammatory cytokines, and thus have been shown to be tolerogenic in steady state, or at best weakly immunogenic (1). Stimulation of iDCs with bacterial products, $\mathrm{T}$ cell-derived signals, and/or inflammatory agonists triggers a differentiation process ("maturation"), accompanied by the expression of costimulatory molecules and cytokines, which shapes the nature and magnitude of T cell-mediated immunity (2). Due to this critical role in the innate-to-adaptive immune transition, vaccines using DCs have been evaluated in the treatment of patients with metastatic melanoma; however, these clinical studies have been disappointing, with objective response rates less than $10 \%$ (3). Multiple factors contribute to the limited success of DC vaccination in melanoma, including the tumor microenvironment, Treg-mediated suppression, immune senescence, as well as incomplete maturation of the DCs used for immunization $(4,5)$. To date, the majority of DC vaccine studies have used either iDCs (GM-CSF/IL-4) or partially matured DCs (GM-CSF/IL-4 plus activation by IL-1 $\beta$, IL-6, TNF- $\alpha$,

Conflict of interest: Wen-Rong Lie is an employee at EMD Millipore. Citation for this article: J Clin Invest. 2013;123(8):3383-3394. doi:10.1172/JCI68395. and/or PGE-2), which express costimulatory molecules but fail to produce IL-12p70 (6). Production of bioactive IL-12p70 requires the coordinated transcriptional regulation of genes encoding the IL-12p35 and IL-12p40 subunits (7). Transcriptional activation of IL-12p70 is dependent on 2 signals: one initiated by CD40 or TLR and the other initiated by IFN- $\gamma(8-10)$. While both signals are necessary for IL-12p35 transcriptional activation, IL-12p40 activation is less dependent on IFN- $\gamma$ signals. Studies using artificial antigenpresenting cells provided the initial evidence for the critical role of IL-12p70, in conjunction with antigen and B7 costimulation, for naive $\mathrm{CD}^{+} \mathrm{T}$ cell expansion and acquisition of effector function (11). Subsequent work in preclinical models confirmed the role of IL-12p70 as a third signal for T cell activation and later demonstrated that either IL-12p70 or type I IFN was necessary for the development of type $1 \mathrm{CD}^{+} \mathrm{T}$ cells $(12,13)$. Among $\mathrm{CD} 8^{+}$ $T$ cells responding to antigen and costimulation, IL-12p70 signaling enforces a gene regulation program that promotes chromatin remodeling and induction of transcription factors, such as T-bet and Eomes, that are important in the differentiation program of this polarized $\mathrm{T}$ cell population, defined as the T-cytotoxic 1 (Tc1) phenotype (14). Systemic administration of IL-12p70 has been demonstrated to have antitumor activity in various preclinical animal models as well as modest activity in cancer patients when given alone or with cancer vaccines (15-17). However, dose-limiting 


\section{Table 1}

Patient characteristics and immunological and clinical outcomes

\begin{tabular}{|c|c|c|c|c|c|c|c|c|}
\hline Patient & Sex & $\operatorname{Age}^{A}$ & Stage $\mathrm{B}^{\mathrm{B}}$ & Site of metastasis & Clinical status & TTPC & Immune respone ${ }^{D}$ & IL-12p70E \\
\hline P1 & M & 47 & 4 (M1a) & Subcutaneous (multiple), lymph node & Complete remission & $9 / 23 / 08 ;>1,416 d$ & 325 & 104,794 \\
\hline P2 & M & 70 & 4 (M1b) & Lung (multiple) & Progressive disease & $1 / 16 / 09 ; 131 d$ & 311 & 902 \\
\hline P3 & M & 53 & 4 (M1a) & Lymph node & Progressive disease & $5 / 29 / 09 ; 81 d$ & 4.4 & 63 \\
\hline P4 & $\mathrm{F}$ & 50 & 4 (M1a) & Subcutaneous (solitary) & Progressive disease & $1 / 15 / 10 ; 74 \mathrm{~d}$ & 62 & 287 \\
\hline P5 & M & 53 & 4 (M1b) & Lung (multiple) & Partial response & $4 / 9 / 10 ; 352 d$ & 240 & 2,101 \\
\hline P6 & M & 38 & 4 (M1c) & Liver (multiple) & Partial response & 4/13/10; $444 d$ & 301 & 2,065 \\
\hline P7 & M & 36 & 4 (M1b) & Lung (multiple), subcutaneous (multiple) & Progressive disease & $3 / 15 / 11 ; 63 d$ & 295 & 793 \\
\hline
\end{tabular}

AAt initiation of treatment (yr). BAccording to The American Joint Committee on Cancer staging system (2009 ed.). CDate of analysis, 08/05/12. Dgp100-specific T cell frequencies for weeks 0-9 (sum); see Figure 2. EProduction levels for D1-D3 (sum; pg/106 DCs/24 h); see Figures 1 and 4.

toxicities associated with systemic IL-12p70 administration have hindered a wider incorporation into investigational cancer vaccine formulations $(18,19)$.

Despite experimental evidence supporting the use of IL-12p70 as a vaccine adjuvant, current human DC vaccine formulations fail to incorporate coordinated CD40/TLR/IFNR signaling as part of the maturation process; thus, it remains to be determined whether vaccination with functionally mature, IL-12p70-producing DCs confers a benefit to humans with cancer. Our aim was to test the hypothesis that immunization with functionally mature, IL-12p70-producing DCs would correlate with antigen-specific immunity and clinical outcomes in patients with metastatic melanoma. In this proof-of-concept clinical trial, patients with newly diagnosed metastatic melanoma were immunized against 3 HLA-A*0201-restricted gp100 melanoma antigen-derived peptides (G154, G209-2M, and G280-9V) $(20,21)$ using autologous peptide-pulsed, CD40L/IFN- $\gamma$-activated mature DCs (mDCs). In this report, we characterized the induction of $\mathrm{T}$ cell immunity by weekly longitudinal monitoring using PBMCs and investigated biomarkers associated with clinical outcome.

\section{Results}

Patient-derived mDCs display varied IL-12p70 production upon CD4OL/ $I F N-\gamma$ activation. To assess the immunological and clinical outcomes upon vaccination with CD40L/IFN- $\gamma$-activated, IL-12p70producing mDCs, 7 newly diagnosed treatment-naive stage IV melanoma patients were enrolled and treated in a pilot phase I clinical trial (Table 1 and Figure 1A). Patients were not prescreened for IL-12p70 production prior to enrollment. The schedule of cyclophosphamide treatment, DC vaccinations, and immunemonitoring timelines is depicted in Figure 1B. Cyclophosphamide treatment with a single dose $\left(300 \mathrm{mg} / \mathrm{m}^{2}\right.$ i.v. $)$ given 3 days prior to $\mathrm{DC}$ vaccination dose 1 (D1) did not significantly reduce Treg frequencies (Supplemental Figure 2; supplemental material available online with this article; doi:10.1172/JCI68395DS1) or absolute lymphocyte counts (data not shown) in any of the 7 patients treated. For D1, fresh PBMCs were initiated into culture for DC generation; the remaining PBMCs were cryopreserved and used to generate subsequent DC vaccine doses. 24 hours after CD40L/ IFN- $\gamma$ activation, each $\mathrm{mDC}$ preparation was assessed for expression of various costimulatory molecules (CD80, CD83, and CD86; data not shown) and cytokine production. Consistent with a previous report (22), DCs derived from cryopreserved PBMCs showed reduced IL-12p70 production (Figure 1C). However, DCs generated from both fresh and frozen PBMCs, as prepared in our trial, retained functional capacity, as shown by their equivalent in vitro stimulatory capacities (data not shown). More importantly, the initial D1 (fresh DCs/fresh PBMCs) and subsequent booster doses (fresh DCs/frozen PBMCs) of DC vaccines resulted in increased frequencies of gp100 peptide-specific $\mathrm{CD}^{+} \mathrm{T}$ cells (Figure 2), demonstrating this scheme to represent a good logistic approach to DC vaccine manufacturing.

Unexpectedly, concentrations of IL-12p70 produced by mDCs varied dramatically among patients (Figure 1C). For example, patient 1 (P1) DCs produced a median of $37,700 \mathrm{pg} / 10^{6} \mathrm{cells} / 24 \mathrm{~h}$, whereas DCs of P3 produced approximately 370 -fold less $(<100 \mathrm{pg} /$ $10^{6}$ cells $/ 24 \mathrm{~h}$ ). Note that the levels shown in Figure 1C (representing D1-D3) were consistent in all vaccine preparations. Diminished IL-12p70 production ( $<1,000 \mathrm{pg} / 10^{6}$ cells $/ 24 \mathrm{~h}$ ) by patient DCs upon CD40L/IFN- $\gamma$ activation was not due to the inability of these cells to respond to stimuli, as significant induction of IL-6, IL-8, and TNF- $\alpha$ production was observed among normal/high (>1 ng/10 cells $/ 24 \mathrm{~h}$ ) and low ( $<1 \mathrm{ng} / 10^{6}$ cells $\left./ 24 \mathrm{~h}\right)$ IL-12p70 producers (Supplemental Figure 3, A and B). Moreover, among a panel of 42 cytokines and chemokines analyzed, no deficiency other than IL-12p70 was observed in the patients studied (data not shown).

CD40L/IFN- $\gamma$-activated $m D C$ vaccination elicits gp100-specific T cell immunity. To examine the kinetics and magnitude of T cell immunity to the gp100-derived peptides G154, G209-2M, and G280-9V upon $\mathrm{mDC}$ vaccination, peripheral blood was collected prior to vaccination and weekly thereafter (Figure 1B). Isolated PBMCs were used to establish individual cultures for each of G154, G209$2 \mathrm{M}$, and $\mathrm{G} 280-9 \mathrm{~V}$. The $\mathrm{CD}^{+} \mathrm{T}$ cell response to each peptide antigen was analyzed using peptide/HLA*A0201 tetramers after a single round of in vitro stimulation for 12 days. This immune monitoring strategy allows for the reliable detection of vaccineinduced $\mathrm{T}$ cell responses in patients, as vaccine-induced $\mathrm{T}$ cell frequencies are often below the lower limit of detection using current ex vivo assays with fresh PBMCs (23). Furthermore, it allows for assessment of the replicative potential of vaccine-induced $\mathrm{T}$ cells based on the multiple cell divisions required for cell expansion in vitro and detection by tetramer assay. Immune monitoring after D4 was not shown, since the peak of the CD8 ${ }^{+} \mathrm{T}$ cell response occurred within the first 9 weeks for all patients (Supplemental Figure 4A). P5 and P7 had detectable immunity to all 3 gp100 peptides prior to vaccination, and these responses increased significantly after immunization (Figure 2). Surprisingly, the peak $\mathrm{T}$ cell response was detected after 1 or $2 \mathrm{mDC}$ vaccine doses in most patients (Supplemental Figure 4A). However, the 2 patients 
A

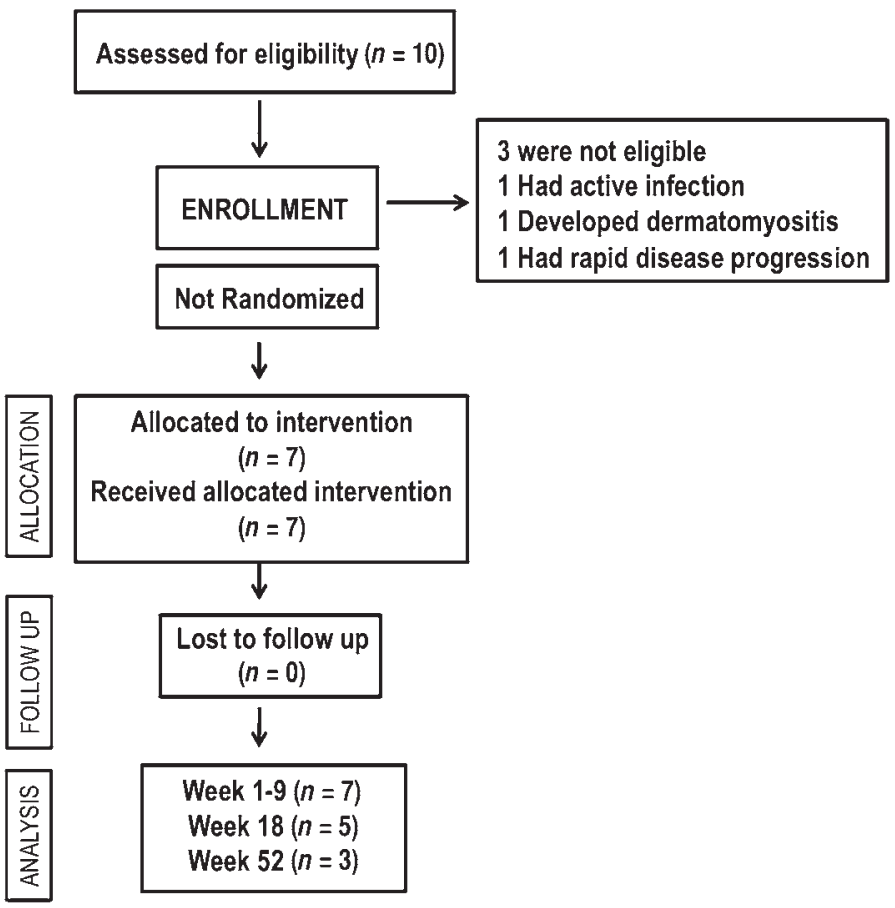

\section{Figure 1}

Clinical trial scheme and ex vivo IL12 p70 production by CD40L/IFN- $\gamma-$ activated DCs (mDCs). (A) Consort diagram. (B) Study timelines depicting cyclophosphamide treatment $(300 \mathrm{mg} /$ $\mathrm{m}^{2}$ i.v.), DC vaccinations (D1-D6), and PBMC sampling for immune monitoring. (C) Ex vivo IL-12p70 levels produced by patient-derived mDCs used for manufacturing D1-D3 (each symbol represent a vaccine dose). DC supernatants were harvested 24 hours after activation, and IL-12p70 concentrations were determined by ELISA. D1 was manufactured using fresh PBMCs (which consistently produced the highest concentration of cytokine) as the source of monocytes, and D2-D6 were prepared using cryopreserved PBMCs. Results represent mean \pm SEM.

B
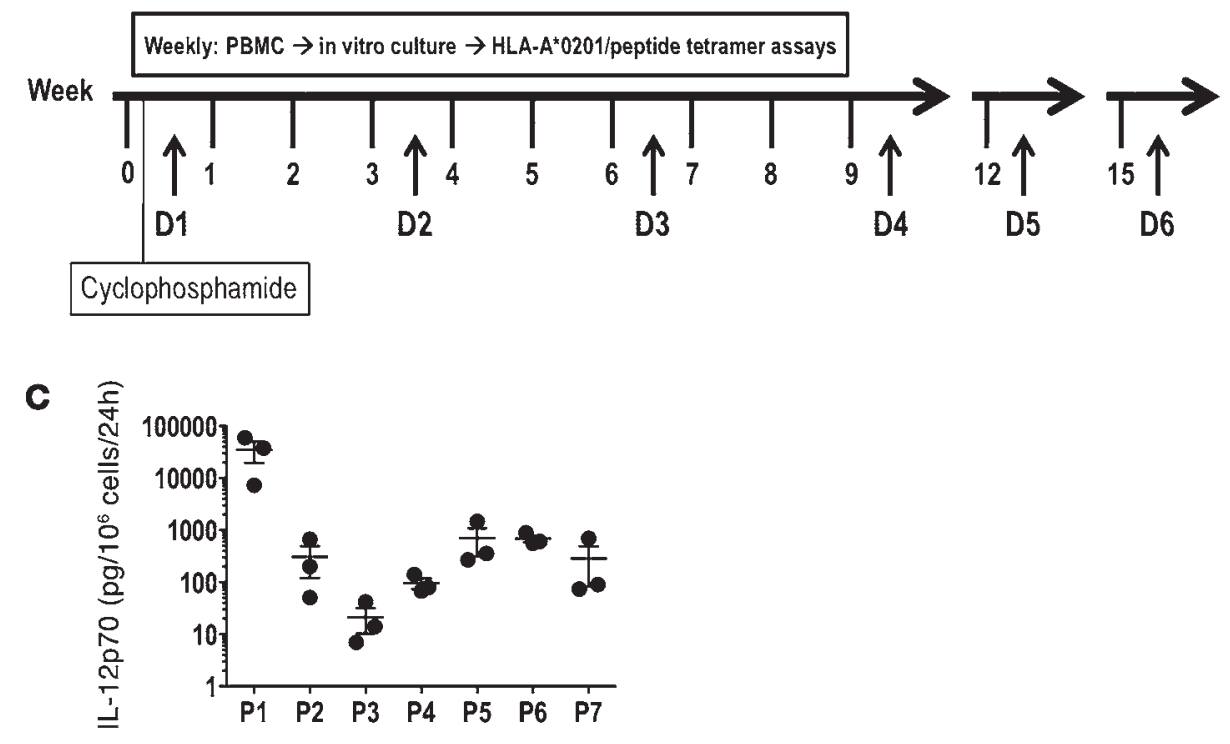

with the lowest gp100-specific T cell responses and the lowest DC IL-12p70 production levels (P3 and P4) had delayed kinetics, with the peak response detected after 3 vaccine doses (Figure 1C, Figure 2 , and Supplemental Figure 4A). Analysis of $\mathrm{CD}^{+} \mathrm{T}$ cell responses to individual gp100-derived peptides indicated that all patients developed immunity to the G209-2M peptide (4.6\%-48\% CD8 ${ }^{+}$ $\mathrm{T}$ cells), while all patients but $\mathrm{P} 3$ developed immunity to the G154 ( $<10 \% \mathrm{CD}^{+} \mathrm{T}$ cells) and G280-9V $\left(11 \%-70 \% \mathrm{CD}^{+} \mathrm{T}\right.$ cells $)$ peptides (Figure 2). Interestingly, $\mathrm{CD}^{+} \mathrm{T}$ cell frequencies in response to the high-affinity G154 peptide were consistently lower than to those observed for the low-affinity G209-2M and G280-9V peptides (Supplemental Figure 4B). Overall, $\mathrm{mDC}$ vaccination resulted in a significant increase in the gp100-specific T cell frequencies for all
3 peptides (Supplemental Figure 4B). Importantly, immunization with CD40L/IFN- $\gamma$-activated mDCs pulsed with G209-2M and G280-9V elicited antigen-specific $\mathrm{CD}^{+} \mathrm{T}$ cells that recognized the naturally processed gp100 antigen and exhibited antigen avidity (i.e., effective concentration at 50\% maximal lysis) ranging $0.1-1$ $\mathrm{nM}$, as determined in standard 4-hour ${ }^{51} \mathrm{Cr}$ release assays (Figure 3 , A and $B$ ). These results suggest that $2 \mathrm{mDC}$ doses are sufficient for the induction of high-avidity $\mathrm{T}$ cells to native gp100 protein in most patients. In the 3 patients that exhibited a confirmed clinical response (P1, P5, and P6; Table 1 and Supplemental Figure 5), gp100-specific memory $\mathrm{T}$ cell responses were detected 6-12 months after the last vaccination (Supplemental Figure 6), despite the fact that ipilimumab followed by temozolomide and steroids 

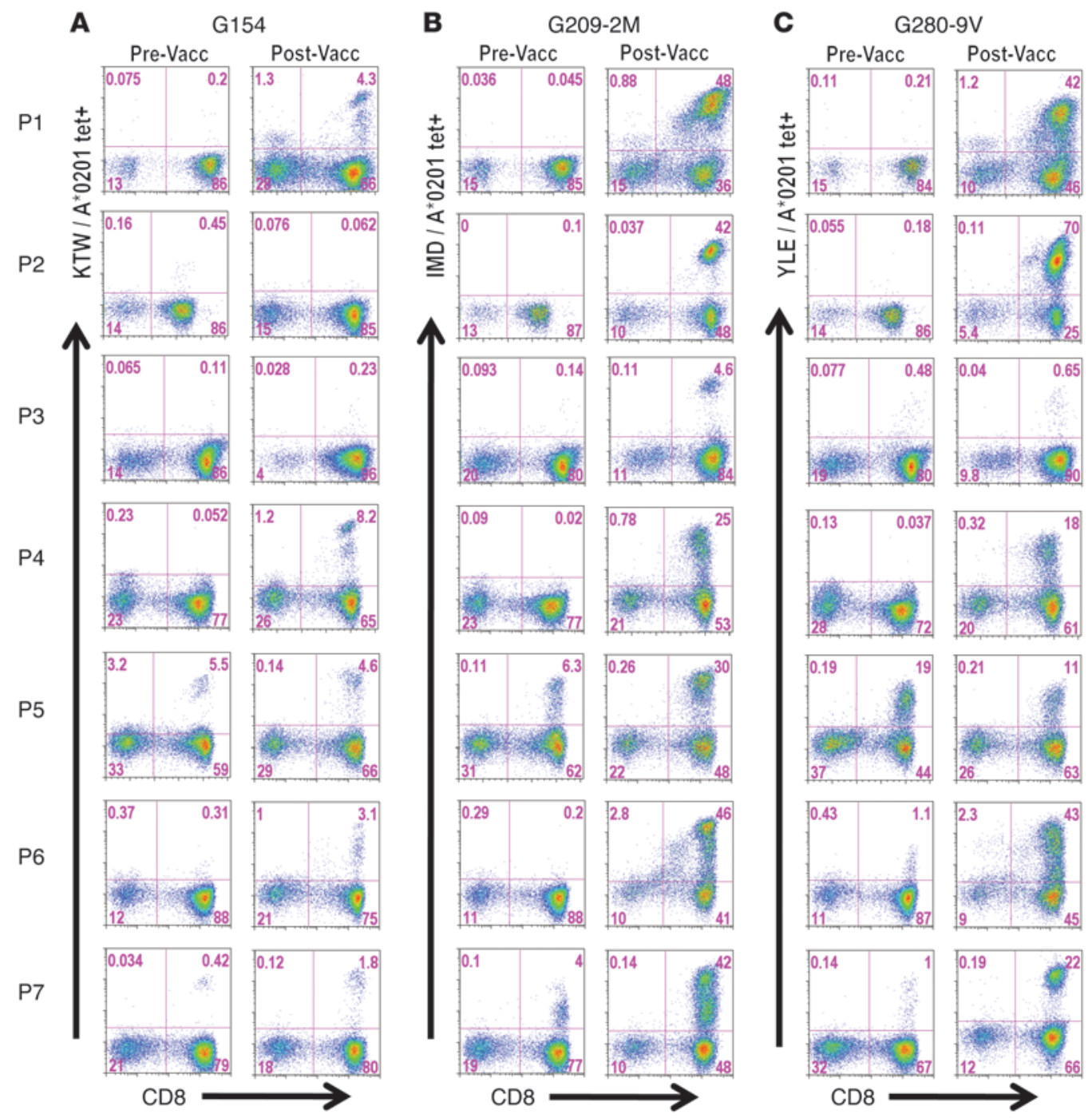

Figure 2

Vaccine-induced CD8+ T cell responses. PBMCs isolated before DC vaccination (pre-vacc) and at peak (post-vacc; see Supplemental Figure 4 for kinetics) were cultured in vitro in the presence of peptide $(40 \mu \mathrm{g} / \mathrm{ml})$ and IL-2 $(50 \mathrm{U} / \mathrm{ml})$ for 12 days. Cultures were stained by addition of corresponding PE-conjugated tetramers (gp100 peptide/HLA-A*0201) followed by a lineage-negative cocktail (FITC-conjugated anti-CD4, -CD14, -CD19, and -CD56) and allophycocyanin-conjugated anti-CD8. Viability dye 7AAD was added to gate out dead cells. Numbers within dot plots represent percent G154 (A), G209-2M (B), and G280-9V (C) tetramer-positive cells in lymph+/CD8+ gated cells.

(P6), ipilimumab (P5), or no additional treatment (P1) had been administered (see trial summary in the supplemental material).

IL-12p70 production by patient $m D C$ c correlates with clinical outcome. Of the 7 patients treated in this pilot trial, 3 had an objective clinical response (P1, P5, and P6; Table 1) as assessed by Response Evaluation Criteria in Solid Tumors (RECIST) criteria (24), and each responding patient had time to progression (TTP) of $>11.5$ months. Cox regression analysis followed by likelihood-ratio test revealed a positive correlation between ex vivo IL-12p70 production by CD40L/IFN- $\gamma$-activated $\mathrm{mDC}$ and TTP $(P=0.0198$; Figure 4). $\mathrm{P} 1$, the patient vaccinated with $\mathrm{mDCs}$ producing the highest amounts of IL-12p70 (Table 1), remained in complete remission $>4$ years after enrollment in the clinical trial (Supplemental Figure 5). In contrast, patients vaccinated with $\mathrm{mDCs}$ producing relatively low amounts of IL-12p70 (<1 ng IL-12p70, sum D1-D3; Table 1) had rapid disease progression, confirmed upon CT imaging per- formed after D3 or D6 (data not shown). Only those patients vaccinated with mDCs producing $>1 \mathrm{ng}$ IL-12p70 (Table 1) had clinical benefit, as defined by increased TTP as well as tumor regression (Supplemental Figure 5). In contrast, a similar analysis found no significant correlation between IL-12p70 production and frequency of vaccine-induced $\mathrm{T}$ cell responses or between frequency of vaccine-induced T cell responses and TTP in this study.

Vaccine-induced $C D 8^{+} T$ cell responses are qualitatively different between clinical responders and nonresponders. Having determined that the magnitude of the vaccine-induced immune response did not correlate with clinical benefit, next we examined whether immunization with high/normal (>1 ng/ $10^{6}$ cells $/ 24 \mathrm{~h}$ ) and low ( $<1 \mathrm{ng} / 10^{6}$ cells $/ 24 \mathrm{~h}$ ) IL-12p70-producing DCs influences the cytokine profiles of the vaccine-induced T cells. G280-9V-specific $\mathrm{CD}^{+} \mathrm{T}$ cells were generated as previously described (25) and restimulated in an antigenspecific manner, and supernatants were collected at 20 hours and 
A
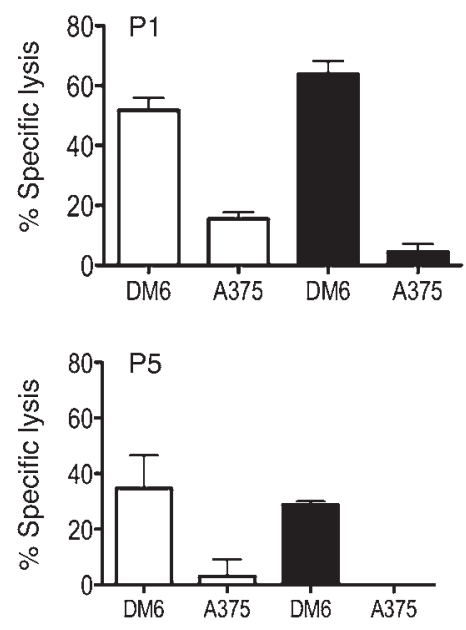

B

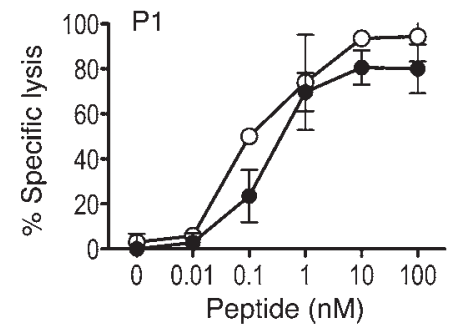

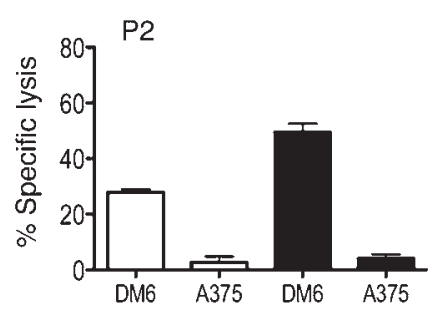
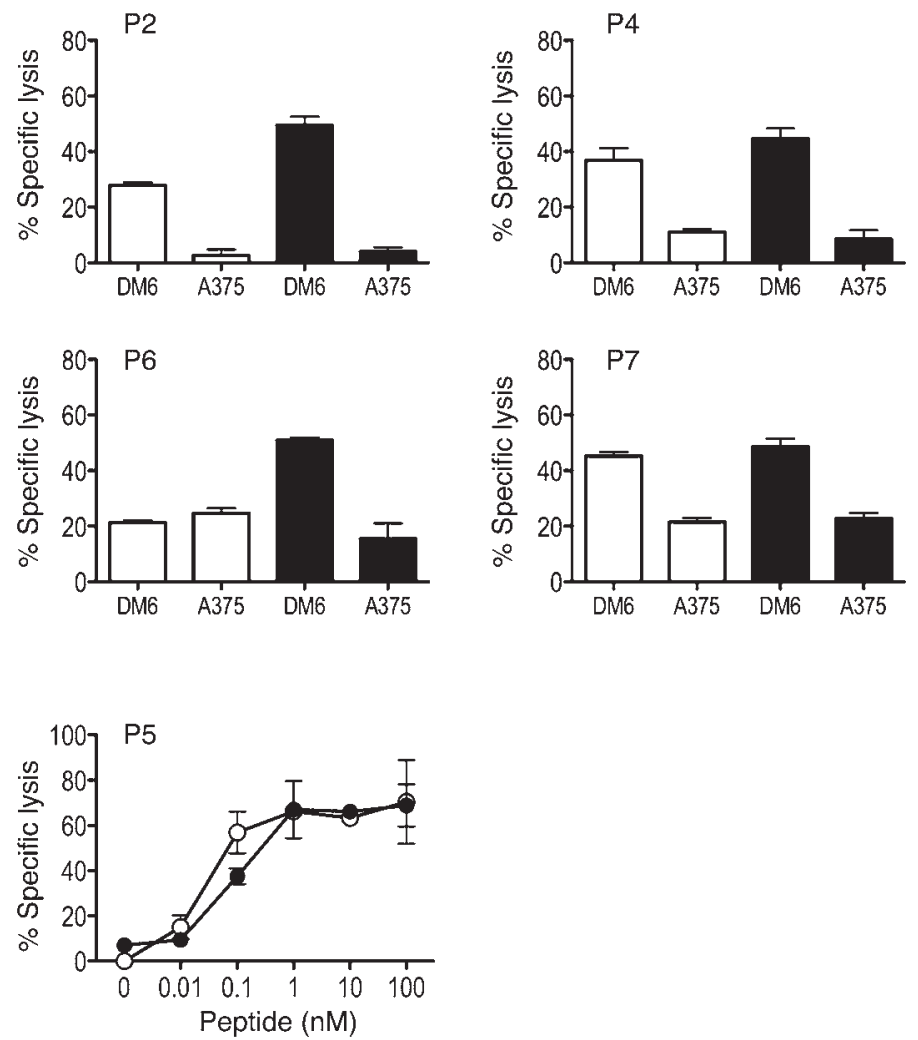

Figure 3

Vaccine-induced T cells recognize native gp100 and display high affinity for antigen. (A) PBMCs collected after D3 were cultured in the presence of G209-2M (white bars and symbols) or G280-9V (black bars and symbols) peptide for 12 days as described in Figure 2 and tested in a standard 4-hour ${ }^{51} \mathrm{Cr}$ release assay for their ability to recognize native gp100 antigen on human melanoma cells lines DM6 (HLA-A2 $\left.{ }^{+} \mathrm{gp} 100^{+}\right)$and $\mathrm{A} 375$ (HLA-A2+gp100-). Percent specific lysis at a 30:1 effector/target ratio is shown; spontaneous lysis was $<10 \%$. Results are representative of 2 experiments. (B) Avidity of G209-2M- and G280-9V-specific T cells was determined in a standard 4-hour ${ }^{51} \mathrm{Cr}$ release assay using peptide titrations and T2 (HLA-A*0201+) cells as targets. Percent specific lysis is shown for each peptide concentration; spontaneous lysis was $<5 \%$. Results are representative of 2 experiments.

tested by a multiplex (42-cytokine) bead assay. Examination of IFN- $\gamma$, IL-5, and IL-13 production levels revealed 2 distinct cytokine profiles among the 6 patients with immunological responses (P3 could not be evaluated because the frequency of gp100-specific $\mathrm{T}$ cells was insufficient for analysis). In 1 group of patients (P1, P5, and P6), IFN- $\gamma$ production was dramatically higher than IL-5 and IL-13, suggestive of a Tc1 bias immune response, while in another group (P2, P4, and P7), higher IL-5 and IL-13 production amounts with less IFN- $\gamma$ was observed, consistent with a Tc2 bias (Figure 5, $\mathrm{A}$ and $\mathrm{B})$. When patients were grouped according to clinical benefit (clinical responder vs. nonresponder), significant differences between these 2 groups were observed in IFN- $\gamma /$ IL-13 and IFN- $\gamma /$ IL-5 ratios $(P=0.0356$ and $P=0.0425$, respectively; Figure 5C). The high IFN- $\gamma / \mathrm{IL}-13$ and IFN- $\gamma / \mathrm{IL}-5$ ratios observed in the patients immunized with high-IL-12p70-producing mDCs (P1, P5, and P6) correlated with an objective clinical response (Table 1). Conversely, vaccination with low-IL-12p70-producing $\mathrm{mDCs}$ resulted in a Tc2-skewed response (low IFN- $\gamma /$ IL-13 or IFN- $\gamma /$ IL-5 ratio), which may be ineffective at promoting tumor regression and correlated with rapid disease progression. Importantly, Tc1 profiles positively correlated with TTP (IFN- $\gamma / \mathrm{IL}-13, P=0.035$; IFN- $\gamma / \mathrm{IL}-5, P=0.030$; Kaplan-Meier log-rank test), such that those patients with IFN- $\gamma$ in excess of IL-13 and IL-5 had the longest TTP. Other cytokines associated with lineage commitment, such as IL-9, IL-10, and IL-17, could not be detected in the supernatants of antigen-stimulated gp100-specific CD8 ${ }^{+} \mathrm{T}$ cells from patients in this study (data not shown). This observation provides evidence that vaccination with IL-12p70-producing (>1 ng/ $10^{6}$ cells $/ 24 \mathrm{~h}$ ) mDCs promotes type 1 immunity that can result in clinical benefit in newly diagnosed patients, as defined by objective tumor regression and improved progression-free survival.

Decreased IL-12p70 production results from impaired IL-12p35 gene activation upon $C D 40 L / I F N-\gamma$ stimulation. Having established a statistically significant correlation between IL-12p70 production and clinical outcome (as measured by TTP; Figure 4), we formally examined whether IL-12p70 production by DCs upon CD40L/ IFN- $\gamma$ activation is defective among melanoma patients. iDCs derived from 10 newly diagnosed treatment-naive stage IV melanoma patients and 10 age- and gender-matched healthy controls were generated, then stimulated with CD40L/IFN- $\gamma$ and supernatants collected 24 hours later. As shown in Figure 6A, and in agreement with our previous results (26), mDCs from healthy controls produced a median IL-12p 70 concentration of $5.5 \mathrm{ng} / 10^{6}$ cells/24 h; the highest IL-12p70 producer among healthy controls was $24 \mathrm{ng} / 10^{6}$ cells $/ 24 \mathrm{~h}$. In contrast, mDCs derived from melanoma patients produced a median IL-12p70 concentration 


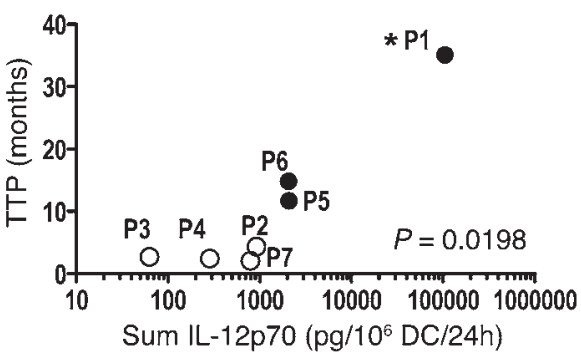

Figure 4

IL-12p70 production and TTP. Cox regression analysis followed by likelihood-ratio test revealed a positive correlation between IL-12p70 production and TTP $(P=0.0198$, log-rank). White symbols represent patients with rapid disease progression. Black symbols represent patients with confirmed clinical response (see Table 1). P1 showed complete remission as of 4 years after initiation of treatment (analysis performed on 08/05/12; asterisk); P5 and P6 showed a partial response, with disease progression observed at or after 11.5 months of treatment initiation. No correlation was observed between IL-12p70 production and immune response or between immune response and clinical outcome.

of $0.65 \mathrm{ng} / 10^{6}$ cells $/ 24 \mathrm{~h}$. This 8 -fold decrease in median IL-12p70 production levels was statistically significant $(P=0.0420)$, despite 1 melanoma patient producing IL-12p70 levels of $>30 \mathrm{ng} / 10^{6}$ cells $/ 24 \mathrm{~h}$. Moreover, mDCs from 7 of the 10 melanoma patients produced IL-12p70 levels of $<1 \mathrm{ng}$, while all healthy controls produced $>1$ ng (Figure 6A).

To better understand the basis for impaired production of bioactive IL-12 (IL-12p70, IL-12p35, and IL-12p40), we examined the synthesis of IL-12p40 and IL-12p35. As IL-12p35 is secreted exclusively as a subunit of the IL-12p70 heterodimer (1:1 ratio with IL-12p40), bioactive IL-12 production is generally accepted to be an indicator of IL-12p35 production (27). As shown in Figure $6 \mathrm{~B}, \mathrm{IL}-12 \mathrm{p} 40$ production was markedly induced in $\mathrm{mDCs}$ in all patients (10.1-177 $\mathrm{ng} / 10^{6}$ cells $/ 24 \mathrm{~h}$ ). A 2.5 -fold difference was observed between the 25 th and 75 th quartiles (20.5 and 52.7 $\mathrm{ng} / 10^{6}$ cells $/ 24 \mathrm{~h}$, respectively), suggesting similar induction of IL-12p 40 production among patients. In contrast, IL-12p70 production varied substantially ( $45 \mathrm{pg}-33 \mathrm{ng} / 10^{6}$ cells $/ 24 \mathrm{~h}$ ) among patients, with an 18 -fold difference between the 25 th and 75 th quartiles ( 63 and $1,170 \mathrm{pg} / 10^{6}$ cells $/ 24 \mathrm{~h}$, respectively). These data suggested that defective IL-12p35 expression might account for the decreased IL-12p70 production. We sought to further confirm this finding using quantitative real-time RT-PCR (qRT-PCR) using $\mathrm{mDCs}$ from the clinical trial participants (no cells were available for P4). As shown in Figure 6C, the IL-12p35 transcript was marginally induced ( $<3$-fold) in DCs from the low IL-12p70 producers (P2, P3, and P7), whereas a >15-fold increase was observed in DCs derived from the high/normal IL-12p70 producers (P1, P5, and P6). Together, these findings suggest that defective IL-12p35 gene transcription observed upon CD40L/IFN- $\gamma$ activation accounts for the impaired IL-12p70 production by melanoma patient DCs.

Impaired IL-12p70 production by patient $m D C$ can be rescued by a unique combination of innate and adaptive activating signals. Prior studies in healthy individuals have demonstrated that TLR agonists can synergize with CD40L and/or IFN- $\gamma$ (28-30) to stimulate IL-12p70 production. In an effort to correct the IL-12p35 deficiency observed upon CD40L/IFN- $\gamma$ activation, DCs derived from clinical trial participants were activated with $\mathrm{CD} 40 \mathrm{~L} / \mathrm{IFN}-\gamma$ in combination with various TLR agonists and IL-12p70 production levels examined. In preliminary experiments using single TLR agonists, we determined that the TLR3 agonist poly I:C and the TLR8 agonist R848 were equipotent when added as single agonists to CD40L/IFN- $\gamma$ (data not shown). Moreover, as shown in Figure 7A, poly I:C, R848, and $\mathrm{CD} 40 \mathrm{~L} / \mathrm{IFN}-\gamma$ in combination enhanced patient DC IL-12p70 production 5- to 160 -fold above that of CD40L/IFN- $\gamma$ activation alone. Importantly, upon combined CD40L/IFN- $\gamma$, poly I:C, and R848 activation, IL-12p70 production by mDCs from P2, P3, P4, and P7 reached levels similar to those observed in healthy individuals (Figure $6 \mathrm{~A}$ and Figure $7 \mathrm{~A}$ ). Thus, the IL-12p70 deficiency observed in patient mDCs upon CD40L/IFN- $\gamma$ activation appears to be pathway dependent, not reflective of an overall dysfunction in IL-12p35 transcription. Finally, as an additional test of functional competence, mDCs activated with CD40L/IFN- $\gamma$, poly I:C, and R848 in combination were evaluated for their capacity to promote the ex vivo expansion of antigen-specific $T$ cells from selected vaccinated patients. As shown in Figure 7, B and C, mDCs activated with combined CD40L/IFN- $\gamma$, poly I:C, and R848 enhanced IL-12p70 production and showed an improved capacity compared with $\mathrm{CD} 40 \mathrm{~L} /$ IFN- $\gamma$ activation alone, stimulating growth of gp 100 -specific $\mathrm{CD} 8^{+}$ $\mathrm{T}$ cells and increasing $\mathrm{T}$ cell frequencies 2 - to 4 -fold, as assessed by gp100/HLA-A*0201 peptide tetramer assay. Together, these results demonstrated that the incorporation of poly I:C and R848 into the DC maturation protocol improved IL-12p70 production by melanoma patient-derived DCs and may promote enhanced antigenspecific $\mathrm{CD} 8^{+} \mathrm{T}$ cell responses.

\section{Discussion}

A novel clinical-grade CD40L reagent was developed to test the hypothesis that immunization with functionally mature IL12p70-producing DCs elicits effective $\mathrm{CD}^{+} \mathrm{T}$ immunity in patients with newly diagnosed advanced melanoma. Immunological responses to the gp100 antigen were observed in 6 of the 7 treated patients, while clinical response (as defined by RECIST criteria) was observed in 3 of 7 patients. Importantly, IL-12p70 levels produced by patient-derived CD40L/IFN- $\gamma$-activated mDCs as well as the development of antitumor $\mathrm{Tc} 1 \mathrm{CD} 8^{+} \mathrm{T}$ cell immunity correlated with TTP. Impairment in IL-12p70 production by CD40L/IFN- $\gamma$ activated mDCs was observed in the 4 clinical nonresponder patients (all with Tc2-skewed immunity), and this deficiency resulted from impaired IL-12p35 subunit transcription. However, incorporating TLR3 and TLR8 signals with CD40L/ IFN- $\gamma$ activation corrected the IL-12p70 production defect in clinical nonresponder patient DCs, suggesting new ways to improve vaccine efficacy in patients with cancer.

Progress in cancer immunotherapy has been hampered by the lack of clinical-grade reagents available to investigators (31); thus, to the best of our knowledge, this study represents the first DC vaccine trial to use the combination of trimeric (cell-bound) CD40L with IFN- $\gamma$ for ex vivo DC maturation prior to administration. Previous human studies have used clinical-grade soluble trimeric $\mathrm{CD} 40 \mathrm{~L}$ as a single agent applied to mDCs ex vivo $(32,33)$, but neither reported or attempted to correlate IL-12p70 production with immunological responses and/or clinical outcomes. More recently, Okada et al. (34) demonstrated, in malignant glioma, the immunogenicity and clinical activity of a poly-ICLC-boosted $\alpha$-type 1 polarized DC vaccine and correlated clinical benefit (as determined by TTP) with the ability of these type 1 polarized DCs to in vitro produce IL-12p70 upon CD40L activation. Our results 
$\mathbf{A}$
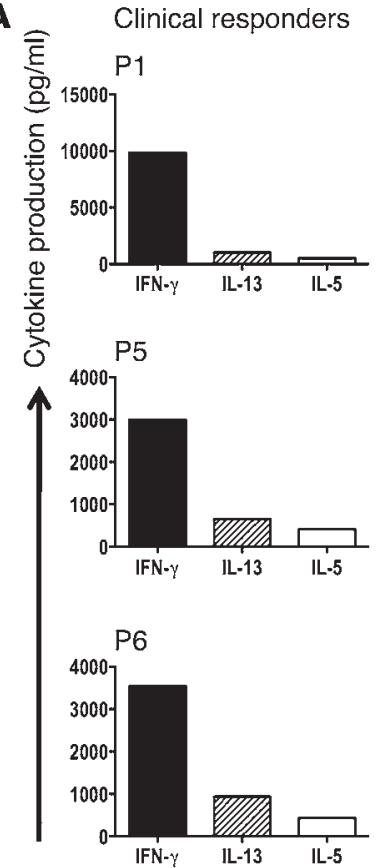

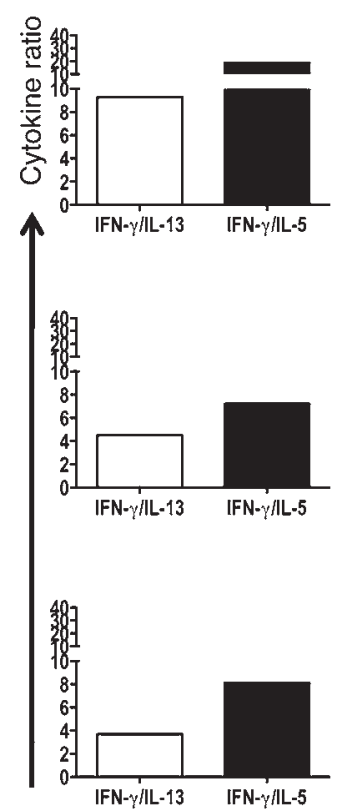

B

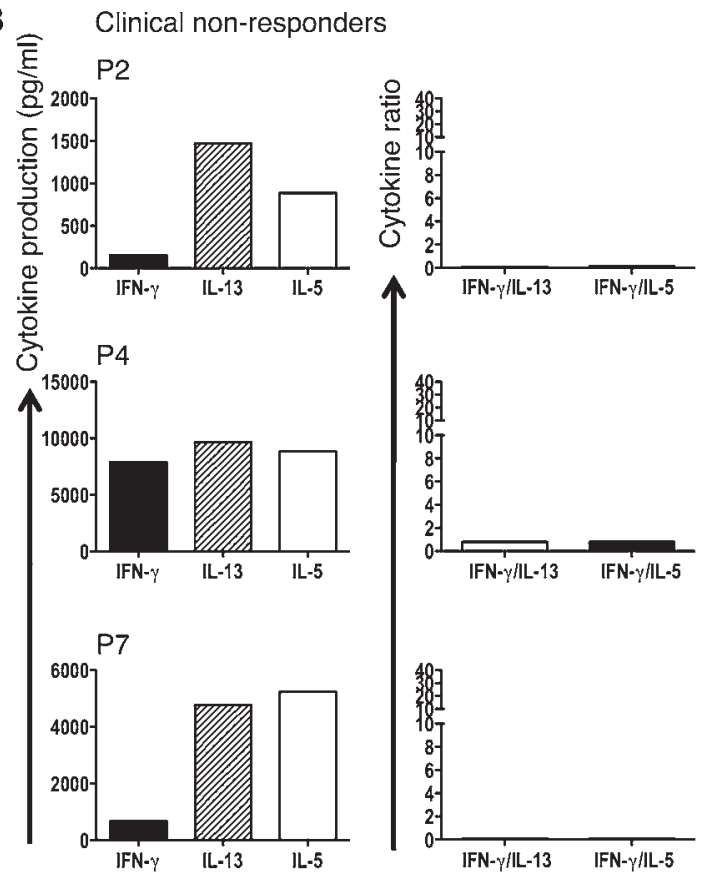

C

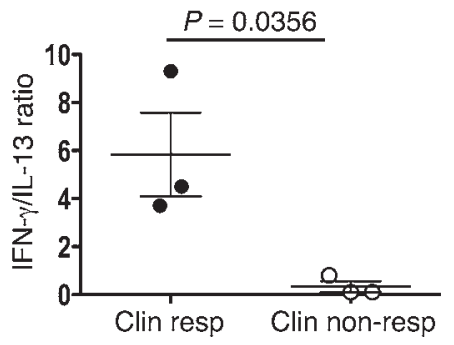

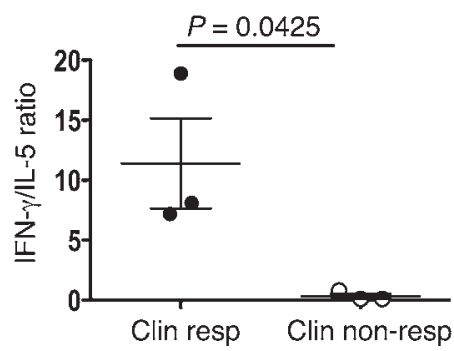

Figure 5

gp100 antigen-specific T cells from clinical responders display a Tc1 phenotype. Purified CD8 ${ }^{+}$T cells were stimulated twice in vitro, and antigenspecific frequencies were determined by peptide/HLA-A 0201 tetramers. T cells were adjusted to $10^{6}$ cell $/ \mathrm{ml}$ and stimulated with antigen, and supernatants were harvested at 20 hours. Cytokine production was determined as described in Methods. (A and B) Patients were grouped as clinical responders (A) and nonresponders (B). To compare production of Tc1 (IFN- $\gamma$ ) and Tc2 (IL-5, IL-13) cytokines among patients, a cytokine index was derived by dividing pg/ml IFN- $\gamma$ by pg/ml IL-13 or IL-5. (C) Cytokine ratios differed among clinical responder and nonresponder patients. $P$ values (unpaired 2-tailed $t$ test) are indicated. Results are representative of 2 experiments.

confirmed and extended these findings by providing additional evidence in melanoma that immunization with antigen-loaded, IL-12p70-producing DC vaccine resulted in the development of $\mathrm{Tc} 1$ antigen-specific $\mathrm{CD}^{+} \mathrm{T}$ cell immunity that correlated with clinical benefit, as defined by radiographic response (RECIST) and improved TTP. Importantly, the 3 highest IL-12p70 producers (P1, $\mathrm{P} 5$, and $\mathrm{P} 6$ ) in our trial were the only patients that had a radiographic response (1 complete remission, 2 partial response), and each was associated with TTP of $>11.5$ months. In contrast, the remaining 4 patients ( $\mathrm{P} 2, \mathrm{P} 3, \mathrm{P} 4$, and $\mathrm{P} 7)$ all had IL-12p70 production of $<1 \mathrm{ng} / 10^{6}$ cells $/ 24 \mathrm{~h}$ and exhibited disease progression with no evidence of tumor regression at any site. Thus, IL-12p70 production levels appear to be a biomarker of clinical benefit (Figure 4), which suggests that optimization of DC vaccine formulations should consider incorporating measurement of IL-12p70 production as a surrogate of vaccine potency and efficacy $(34,35)$.

Despite several comparative studies in humans $(3,36)$, the optimal route of DC administration remains to be defined. Based on immunological and clinical outcomes reported by Timmerman et al. (37) using i.v. infused DCs in non-Hodgkin's lymphoma, we chose to administer CD40L/IFN- $\gamma$-activated mDCs by i.v. infusion. Labeling studies in patients have shown that i.v. injected DCs traffic to the lung and subsequently redistribute to liver, spleen, and bone marrow $(38,39)$. Interestingly, P6 presented multiple liver metastases and achieved partial clinical response after vaccination, suggesting an effect of IL-12p70-producing DCs at or near the hepatic lesions. Additionally, our results demonstrated that i.v. administration of DCs induced T cell immunity, which suggests that the quality of immune response maybe more dependent on the maturation status of DCs than on the route of administration. However, recent studies have suggested that other routes of vaccine administration might be superior (40,41); additional investigation is warranted in this area to further optimize vaccine efficacy.

DC dysfunctions in cancer patients have been previously described; most are predicated on tumor-derived factors that suppress DC differentiation, maturation, or function within the 
A

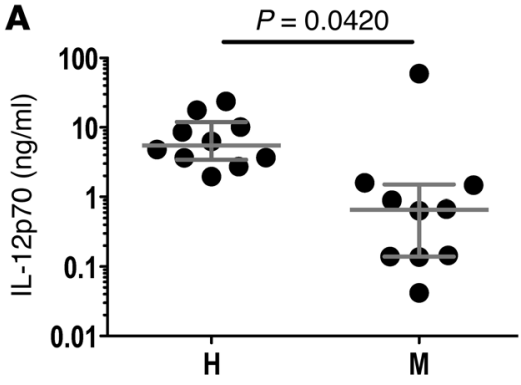

B

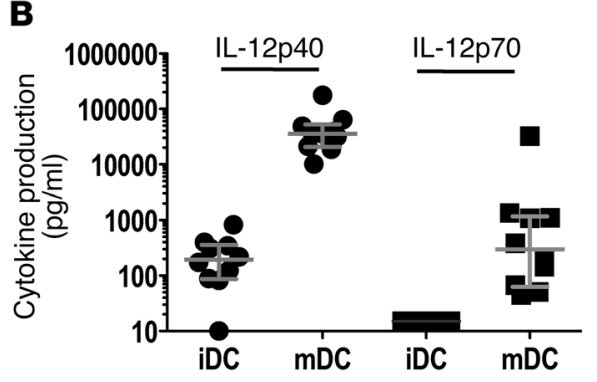

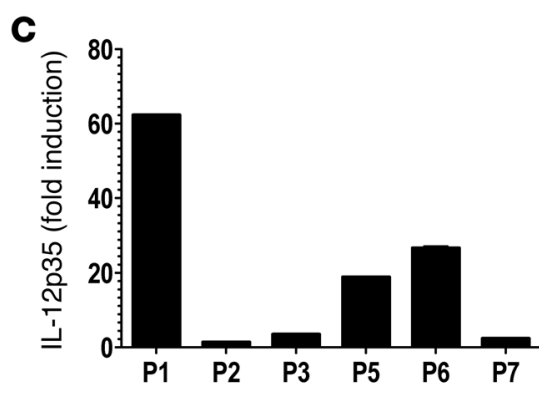

Figure 6

IL-12p70 production and IL-12p35 transcription by mDCs derived from patients with melanoma. (A) DCs from age- and gender-matched healthy donors $(\mathrm{H})$ and melanoma patients $(\mathrm{M})$ were activated with CD40L/IFN- $\gamma$ for 24 hours, and supernatants were harvested and assayed for IL12 p70 production by ELISA. Horizontal lines and error bars denote median and interquartile range. $P$ value (Wilcoxon matched-pairs test) is indicated. (B) Patient DCs were activated with CD40L/IFN- $\gamma$ for 24 hours, supernatants were collected, and IL-12p40 and IL-12p70 production was measured by ELISA. Results are shown for 10 melanoma patients. Horizontal lines and error bars denote median and interquartile range. (C) To examine IL-12p35 gene activation, DCs were activated with CD40L/IFN- $\gamma$ for 6 hours, cells were harvested and washed, and total RNA was prepared. Total RNA was also prepared from iDCs. Using primers specific for IL-12p35 and CD11c (DC lineage marker), qRT-PCR was performed and analyzed using the relative standard method. Results were normalized to CD11c, and values are expressed as fold IL-12p35 induction in $\mathrm{mDC}$ relative to iDCs. Results are representative of 2 experiments.

context of the tumor microenvironment $(4,42)$. The list of tumorderived factors includes IL-10, VEGF, M-CSF, TSLP, and TGF- $\beta 1$ as well as prostaglandins and gangliosides $(5,43)$. The observed defect in IL-12p70 synthesis upon CD40L/IFN- $\gamma$ activation in 7 of 10 patients was also suggestive of a DC dysfunction, albeit one that is likely dependent on activation method (CD40L/IFN- $\gamma$ ) and perhaps independent of tumor-derived factors. Our observation that incorporation of innate signals (TLR3 and TLR8 agonists) to the activation protocol restored the capacity of patient's DCs to produce IL-12p70 at levels similar to those observed in healthy individuals suggests the IL-12p35 deficiency to be pathway specific. Interestingly, defective IL-12p70 production by neonate DCs has been proposed to account for impaired Th1 responses in human newborns (44). In neonate DCs, similar to our study using adult monocyte-derived DCs, selective deficiency in IL-12p70 production resulted from impaired IL-12p35 transcription upon activation. Goldman and coworkers have identified defective nucleosome remodeling (at the SP-1 site) of the IL-12p35 promoter and lack of IRF-3 phosphorylation as mechanisms that may account for impaired IL-12p35 transcription in newborn-derived DCs $(45,46)$. However, IFN- $\gamma$ treatment of neonate DCs can restore IL-12p35 transcription and IL-12p70 synthesis. In contrast, in melanoma patient-derived DCs, impaired IL-12p35 transcription was corrected by addition of TLR agonists, but not by increasing concentrations of IFN- $\gamma$ (data not shown), which suggests that a distinct mechanism may account for the impairment. Indeed, preliminary studies examining STAT-1 phosphorylation and nuclear translocation of IFN-responsive factors (IRF-1, IRF-8, and IRF3) showed no defect in the IFN signaling pathway among DCs derived from the nonresponder patients (data not shown).

Substantial evidence supports the hypothesis that Th $2 / \mathrm{Tc} 2$ immune polarization correlates with worse disease outcome in patients with cancer (47). Previous work using melanoma antigen-specific $T$ cells from patients confirms an immune bias with deviation toward the Th2/Tc2 phenotype (48-50). Interestingly, this type 2 immune bias could be partially corrected by antigen stimulation in vitro using IL-12p70-producing mDCs (48). Our present results revealed that low-IL-12p70-producing mDCs, like water-in-oil emulsions such as Montanide (51), effectively primed an immune response to the gp100 antigen; however, the quality of the ensuing $\mathrm{T}$ cell response is insufficient to elicit tumor regression. Moreover, the magnitude or duration of $\mathrm{CD}^{+} \mathrm{T}$ cell immunity after immunization was not markedly influenced by IL-12p70 concentration - although P3, the patient that produced no detectable IL-12p70, developed weak, transient $\mathrm{T}$ cell immunity against only G209-2M, whereas the remaining 6 patients developed sustained immunity against all 3 gp100-derived peptides. Rather, the striking bias toward type 1 immunity among the normal/high IL12 p70 producers was consistent with past observations in murine models that show the direct causal influence of IL-12p70 on Th1 lineage commitment $(52,53)$. The positive correlation observed between cytokine ratios (IFN- $\gamma / \mathrm{IL}-13$ and IFN- $\gamma /$ IL-5) and TTP was a finding of key importance, providing further support for IL-12p70 as a critical signal in the induction of therapeutic type 1 antigen-specific $\mathrm{CD}^{+} \mathrm{T}$ cell immunity in patients. Our data may also provide an explanation for the limited success of various adjuvants, as well as past DC vaccine trials in cancer, which have not incorporated IL-12p70 $(3,54)$. Future studies using DC activation protocols incorporating sequential activation signals, such as TLR3 and TLR8 agonists, with CD40L/IFN- $\gamma$ should lead to enhanced IL-12p70 production, which is predicted by various investigators to elicit therapeutic antitumor type 1 immunity $(2,55-57)$.

Sample size estimates for investigator-initiated, first-in-human clinical trials has become a topic of contention, driven principally by the requirement for statistical power balanced by investigation of a biologic proof of principle (58). Implicit in the testing of novel protein-, gene-, or cell-based therapies at single academic medical centers is cost. The results of our study support a model of adaptive clinical development that requires initial testing of expensive therapeutics in a limited number of patients selected on the basis of phenotype (disease) or genotype with a focus on discovery, rather than a well-defined regulatory endpoint. Recent examples that highlight a similar approach of evaluating novel cell therapies in a limited number of patients include trials with chimeric antigen receptor $\mathrm{T}$ cell gene therapy for leukemia (59) and $\alpha$-galactosylceramide-loaded DC vaccination for myeloma (60). 
$\mathbf{A}$
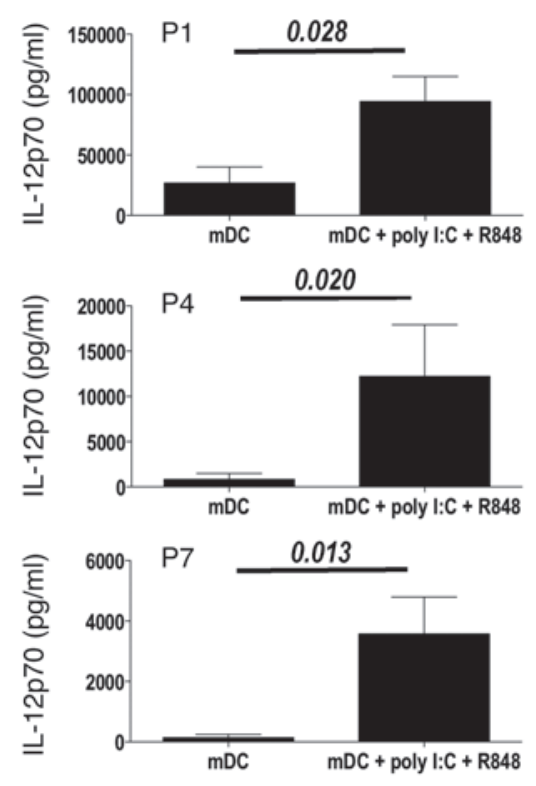
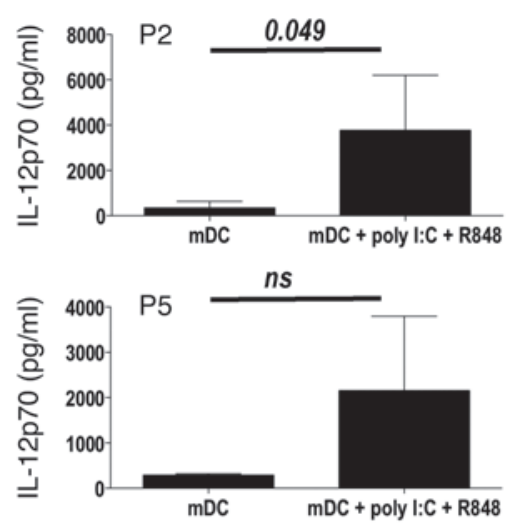
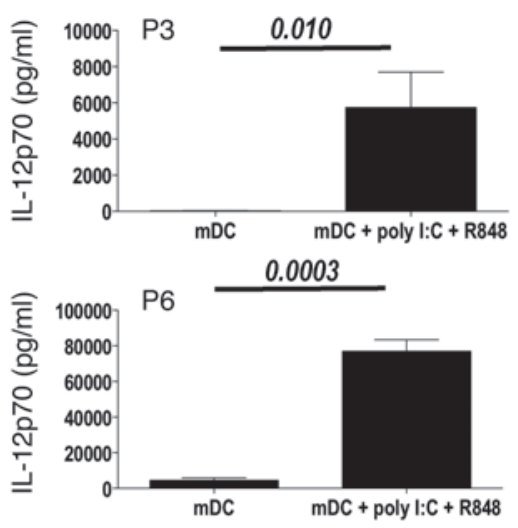

B
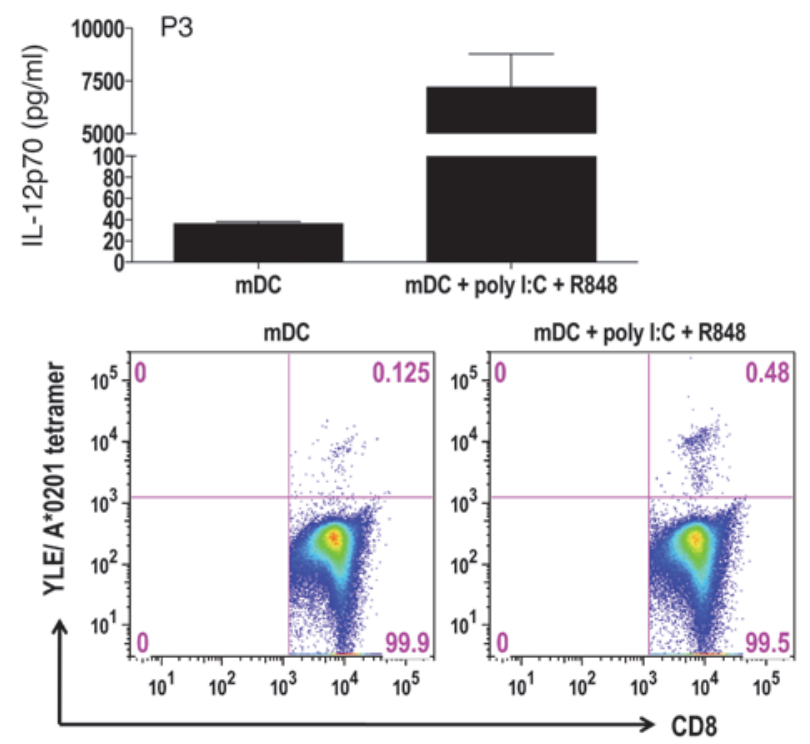

C
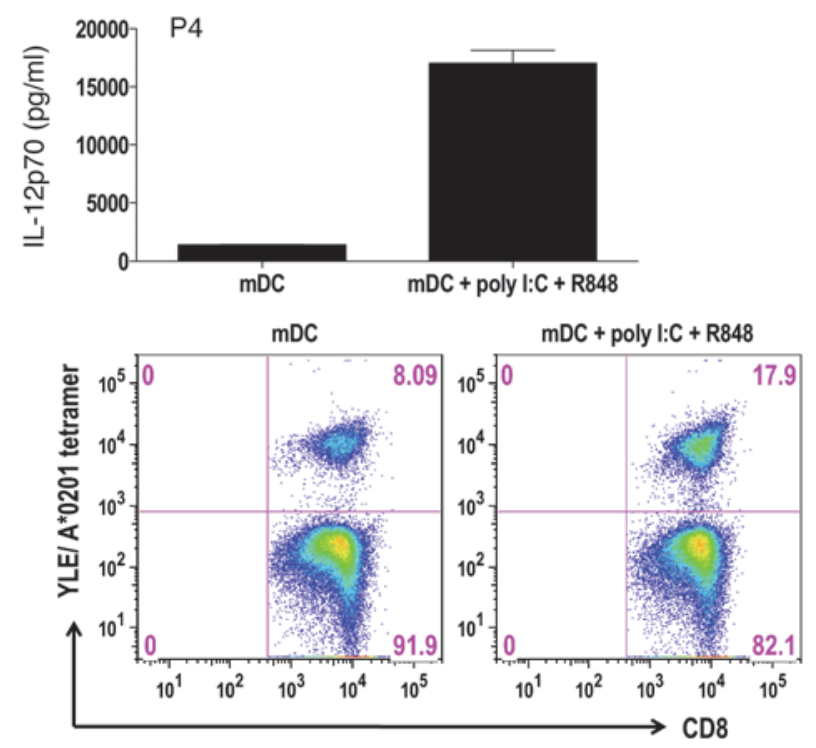

\section{Figure 7}

IL-12p70 production and ex vivo antigen-specific T cell responses stimulated by CD40L/IFN- $\gamma+$ poly I:C + R848-activated DCs. (A) iDCs were stimulated for 24 hours with CD40L/IFN- $\gamma$ (mDCs), alone or in combination with poly I:C (5 $\mu \mathrm{g} / \mathrm{ml}$; TLR3 agonist) and R848 (5 $\mu \mathrm{g} / \mathrm{ml}$; TLR8 agonist), and supernatants were assayed for IL-12p70. Results are those obtained in 2 experiments. $P$ values (paired 2-tailed $t$ test) are indicated. (B and C) DCs derived from P3 and P4 were activated for 24 hours with CD40L/IFN- $\gamma$, alone or in combination with poly I:C and R848, and supernatants were analyzed for IL-12p70. Additionally, activated DCs were pulsed with G280-9V peptide (40 $\mu \mathrm{g} / \mathrm{ml})$ and used for stimulation of purified CD8 ${ }^{+} \mathrm{T}$ cells (see Methods). G280-9V-specific T cell frequencies within the CD8 ${ }^{+} \mathrm{T}$ cell population was determined at day 12 using YLE/ HLA-A*0201 tetramers and anti-CD8 mAb. Results are representative of 3 experiments.

In summary, this proof-of-concept clinical study provided evidence that IL-12p70 produced by antigen-loaded mDCs dictates T cell lineage commitment toward the Tc1 (versus Tc2) phenotype, which then influences disease response (or progression) among patients with minimal tumor burden. These results highlight the critical role of IL12 p70 in developing $\mathrm{CD}^{+} \mathrm{T}$ cell immunity and the potential value of this cytokine as a surrogate for vaccine efficacy and also suggest new strategies to enhance $\mathrm{T}$ cell immunity in patients with cancer.

\section{Methods}

Human subjects. Eligible adult patients with newly diagnosed treatmentnaive (ECOG performance status 0) stage IV cutaneous melanoma were enrolled in this clinical trial. All subjects were HLA-A $0201^{+}$, had gp $100^{+}$ biopsy-proven (HMB45+, immunohistochemistry) melanoma metastases, had no evidence of autoimmune disorder, and were negative for HIV, HBV, and HCV. Leukapheresis was performed to obtain PBMCs from patients and healthy donors through the Barnes Jewish Hospital blood bank. For 
trial patients, leukapheresis was performed prior to treatment and after D3 and D6. Patients were not prescreened for IL-12p70 DC production prior to treatment. Prior to treatment, baseline imaging was performed by MRI scan of brain and CT scan of the chest/abdomen/pelvis with i.v. contrast.

Peptides. gp100-derived peptides G154 (KTWGQYWQV), G209-2M (IMDQVPFSV), and G280-9V (YLEPGPVTV) and CMV pp65-derived peptide 495 (NLVPMVATV) were obtained lyophilized (>95\% purity; American Peptide Company). Peptides were dissolved in 1\% DMSO in sterile water and tested for sterility, purity, endotoxin, and mycoplasma.

Cyclophosphamide treatment and DC preparation. Cyclophosphamide (300 $\mathrm{mg} / \mathrm{m}^{2}$ ) was given 72 hours prior to D1 with the intention of eliminating Tregs (61). Treg quantification was performed as described in Supplemental Figure 2. All mDC vaccine doses were prepared at the time of immunization from either freshly isolated (D1) or cryopreserved (D2-D6) PBMCs (all derived from the same leukapheresis collection). A GMP-grade CD40Lexpressing $\mathrm{K} 562$ cell line (referred to as $\mathrm{K} 463 \mathrm{H}$ ), used for maturation of DCs, was generated, selected, and maintained under serum-free (Stemline, S1694 media) conditions (see Supplemental Figure 1). For each vaccine dose, monocyte-derived iDCs were generated as described previously (62) by culturing the PBMC adherent fraction in RPMI 1640 with $1 \%$ human AB-serum (DC media) supplemented with $100 \mathrm{ng} / \mathrm{ml}$ GM-CSF (Berlex) and $20 \mathrm{ng} / \mathrm{ml} \mathrm{IL-4} \mathrm{(CellGenix).} 6$ days after culture initiation, iDCs were harvested, washed in PBS, and cultured for an additional 24 hours in DC media (iDC control) or DC media with irradiated (100 Gy) K463H (5:1 $\mathrm{DC} / \mathrm{K} 463 \mathrm{H}$ ratio) and $100 \mathrm{U} / \mathrm{ml} \mathrm{IFN- \gamma}$ (Actimmune; InterMune Inc.) to generate mDCs. Comparison of the $\mathrm{K} 463 \mathrm{H}$ line with other commercially available CD40L reagents in IL-12p70 induction is shown in Supplemental Figure 1, B and C. 2 hours prior to infusion, mDCs were pulsed $\left(50 \mu \mathrm{g} / 10^{6}\right.$ cells $\left./ \mathrm{ml}\right)$ separately with 1 of 4 peptides: G154, G209-2M, G280$9 \mathrm{~V}$, or CMV pp65. For D1 only, influenza virus vaccine (Sanofi Pasteur) was added to provide a source of recall antigen for $\mathrm{CD} 4^{+} \mathrm{T}$ cells. For infusion, mDCs were resuspended in $50 \mathrm{ml}$ normal saline supplemented with $5 \%$ human serum albumin and administered over 30 minutes by i.v. infusion after premedication with $650 \mathrm{mg}$ acetaminophen.

DC immunizations. $\mathrm{mDC}$ infusions were given i.v. every 3 weeks for 6 doses in the outpatient clinic. A restaging CT scan of the chest/abdomen/ pelvis with i.v. contrast was performed after D3 and D6 and then every 2 months thereafter until disease progression. If clinical or radiographic disease progression was evident, the patient was removed from the study. For D1, patients received $1.5 \times 10^{7} \mathrm{DCs}$ per peptide $\left(6 \times 10^{7} \mathrm{DCs}\right.$ total); for D2-D6, patients received $5 \times 10^{6}$ DCs per peptide $\left(2 \times 10^{7} \mathrm{DCs}\right.$ total). The purpose of this trial was to determine the safety, tolerability, and clinical and immunological outcomes of immunization using peptide-pulsed CD40L/IFN- $\gamma$ mDCs. Patients underwent clinical evaluation prior to each $\mathrm{mDC}$ infusion. Toxicities and adverse effects were graded according to the National Cancer Institute Common Toxicity Scale (version 3.0). Clinical response was assessed by measurement of assessable metastatic deposits by CT scan, MRI scan, or direct measure of cutaneous deposits. The RECIST (v1.0) group system was used (24).

Immunologic monitoring. Immunologic analysis to evaluate the kinetics and magnitude of $\mathrm{T}$ cell response to gp100 peptides was performed using PBMCs collected weekly (prior to vaccination and until week 21; Figure 1B). Fresh PBMCs obtained by Ficoll-Hypaque gradient centrifugation were adjusted to $2 \times 10^{6}$ cells $/ \mathrm{ml}$ in Stemline media (Sigma-Aldrich) containing $5 \%$ human AB-serum, and dispersed at $1 \mathrm{ml} /$ well in 24 -well plates. Cultures were set up for the gp100 peptides and the CMV pp65 peptide (positive peptide control; data not shown). Cultures were pulsed with 40 $\mu \mathrm{g} / \mathrm{ml}$ peptide and $50 \mathrm{U} / \mathrm{ml} \mathrm{IL-2} \mathrm{fed} \mathrm{starting} \mathrm{at} 48$ hours and every other day thereafter. On day 12 (peak of response; our unpublished observation), cultures were harvested, counted, and stained for flow cytometry analysis.
To assess the antigen-specific T cell frequency, cells were stained with HLAA*0201/peptide tetramers (Beckman Coulter) for 30 minutes at room temperature, followed by addition of FITC-conjugated CD4, CD14, CD19, and CD56 and allophycocyanin-conjugated CD8 (Invitrogen) for 15 minutes at $4^{\circ} \mathrm{C}$. Cells were washed and resuspended in FACS buffer, and 7AAD was added 5 minutes before analysis. Control CMV pp65-specific $\mathrm{CD}^{+} \mathrm{T}$ cells were detected in all CMV-seropositive patients before and after immunization (data not shown). A negative HLA-A*0201/HIV gag peptide tetramer control was included. 25,000 events in the $\mathrm{CD}^{+}$gate were collected using a hierarchical gating strategy that included FSC/SSC and excluded 7AAD (dead) cells and $\mathrm{CD} 4^{+} \mathrm{CD} 14^{+} \mathrm{CD} 19^{+} \mathrm{CD} 56^{+}$cells. Data were acquired and analyzed using Flow-Jo software.

Cytokine production. DC IL-12p70 and IL-12p40 production was measured by ELISA (eBioscience) according to the manufacturer's instructions. Production of additional cytokines and chemokines by DCs was determined using MILLIPLEX MAP Human Cytokine Panels I and II (EMD Millipore). For production of cytokines by T cells, G280-9V-specific $\mathrm{T}$ cells were expanded using mDCs and AT-SCT as described previously (25). The frequency of antigen-specific T cells after secondary stimulation was $2 \%-52 \%$, as determined by HLA-A*0201/peptide tetramers (NIH tetramers Facility or Beckman Coulter). T cells were restimulated as described previously (25), supernatants were collected at 24 hours, and production of cytokines was determined using MILLIPLEX MAP Human Cytokine Panel I (EMD Millipore).

qRT-PCR. qRT-PCR was performed as described previously (26). cDNAs were prepared ( $2 \mu \mathrm{g}$ total RNA), and cDNA samples were amplified in triplicate using a GeneAmp 5700 sequencer detector (Applied Biosystems). Primers used were IL-12p35 (Hs00168405_m1) and ITGAX (integrin alpha $\mathrm{X}$, referred to herein as CD11c; Hs01015070_m1). Transcript levels were calculated using the relative standard curve method, using CD11c transcript levels to normalize values.

${ }^{51} \mathrm{Cr}$ release and $\mathrm{T} 2$ assays. ${ }^{51} \mathrm{Cr}$ release assays to measure specific lysis have been described previously $(26,62)$. Melanoma cell lines DM6 (HLA$\mathrm{A}^{+}{ }^{+} \mathrm{gp} 100^{+}$) and $\mathrm{A} 375$ (HLA-A2 $\left.{ }^{+} \mathrm{gp} 100^{-}\right)$were labeled with $25 \mu \mathrm{Ci}{ }^{51} \mathrm{Cr}$ for 1 hour, washed, and tested as targets in a standard 4-hour assay. Effectors were generated using PBMCs collected after D3 and cultured for 12 days in the presence of peptide $(40 \mu \mathrm{g} / \mathrm{ml})$ and IL-2 $(50 \mathrm{U} / \mathrm{ml}$ every other day). Vaccine-induced antigen-specific $\mathrm{T}$ cells were characterized using HLAA*0201/peptide dextramers (Immudex). To determine the avidity (effective concentration at $50 \%$ maximal lysis) of vaccine-induced $\mathrm{T}$ cells for antigen, T2 cells were pulsed with titrated G209-2M or G280-9V peptide concentrations for 1 hour in serum-free media followed by ${ }^{51} \mathrm{Cr}(25 \mu \mathrm{Ci})$ labeling for 1 hour, washed twice, and tested using vaccine-induced gp100-specific $\mathrm{T}$ cells in a standard 4-hour assay.

Statistics. Student's $t$ tests were 2-tailed (GraphPad Prism software, version 5.0). Data are presented as mean $\pm 1 \mathrm{SD}$, unless otherwise indicated. Cox regression analysis followed by likelihood-ratio test was used to evaluate whether $\left(\log _{\mathrm{e}}\right)$ IL-12p70 (sum) production added statistically significant information to a model of TTP. Kaplan-Meier TTP model was used to test whether cytokine ratios added statistically significant information to a model of TTP. Wilcoxon matched-pairs analysis was used to compare IL12 p70 production between patients and healthy donors (GraphPad Prism software, version 5.0). All $P$ values less than 0.05 were considered significant, except the Cox proportional hazard model, which used a lower threshold of significance $(P<0.048)$ to adjust for 1 interim analysis of this endpoint.

Study approval. This study (IRB no. 07-0652) was approved by the Siteman Cancer Center Protocol Review and Monitoring Committee and the Washington University School of Medicine Human Research Protection Office. All patients provided written informed consent for the clinical study. The FDA approved procedures for DC manufacturing and admin- 
istration according to BB-IND 13590. All healthy volunteers and patients that did not receive treatment on study provided written informed consent prior to blood donation.

\section{Acknowledgments}

We thank Janet Connolly, Daniel Link, and Todd Fehniger for critical reading of the manuscript; John DiPersio for stimulating discussion; and M. Dynis, C. Rush, M. Rettig, M. Sands, T. Hansen, B. Siegel, R. Schmidt, B. Swaney, and M. Colonna for advice and assistance. We gratefully acknowledge M. Anadkat, R. Fields, J. Moley, J. Steel, and B. Tan for providing superb clinical care of the study patients. A. Huang was a 2008-2009 Doris Duke Research Scholar from Mount Sinai School of Medicine. We thank the Siteman Cancer Center at Washington University School of Medicine and Barnes-Jewish Hospital for the use of the Flow Cytometry
Core, the Imaging and Response Assessment Core, the Clinical Trials Core, and the Biologic Therapy Core that provided cGMPcompliant facilities to conduct this clinical trial. We thank the NIH Tetramer Core Facility (Emory University) for the G280-9V tetramer and Immudex for dextramers. We thank the patients and their families for their dedicated participation in this study.

Received for publication December 18, 2012, and accepted in revised form May 6, 2013.

Address correspondence to: Beatriz M. Carreno, Washington University School of Medicine, Division of Oncology, 660 South Euclid Avenue, Campus Box 8007, St. Louis, Missouri 63110, USA. Phone: 314.362.9407; Fax: 314.362.9333; E-mail: bcarreno@dom.wustl.edu.
1. Steinman RM. Decisions about dendritic cells: past, present, and future. Annu Rev Immunol. 2012;30:1-22.

2. Macagno A, Napolitani G, Lanzavecchia A, Sallusto F. Duration, combination and timing: the signal integration model of dendritic cell activation. Trends Immunol. 2007;28(5):227-233.

3. Engell-Noerregaard L, Hansen TH, Andersen MH, Thor Straten P, Svane IM. Review of clinical studies on dendritic cell-based vaccination of patients with malignant melanoma: assessment of correlation between clinical response and vaccine parameters. Cancer Immunol Immunother. 2009;58(1):1-14.

4. Ma Y, Aymeric L, Locher C, Kroemer G, Zitvogel L. The dendritic cell-tumor cross-talk in cancer. Curr Opin Immunol. 2011;23(1):146-152.

5. Gabrilovich DI, Ostrand-Rosenberg S, Bronte V. Coordinated regulation of myeloid cells by tumours. Nat Rev Immunol. 2012;12(4):253-268.

6. Jonuleit $\mathrm{H}$, et al. Pro-inflammatory cytokines and prostaglandins induce maturation of potent immunostimulatory dendritic cells under fetal calf serum-free conditions. Eur J Immunol. 1997;27(12):3135-3142.

7. Vignali DA, Kuchroo VK. IL-12 family cytokines: immunological playmakers. Nat Immunol. 2012;13(8):722-728.

8. Hayes MP, Wang J, Norcross MA. Regulation of interleukin-12 expression in human monocytes: selective priming by interferon-gamma of lipopolysaccharide-inducible p35 and p40 genes. Blood. 1995;86(2):646-650.

9. Snijders A, Kalinski P, Hilkens CM, Kapsenberg ML. High-level IL-12 production by human dendritic cells requires two signals. Int Immunol. 1998;10(11):1593-1598.

10. Mosca PJ, et al. A subset of human monocytederived dendritic cells expresses high levels of interleukin-12 in response to combined CD40 ligand and interferon-gamma treatment. Blood. 2000;96(10):3499-3504.

11. Curtsinger JM, et al. Inflammatory cytokines provide a third signal for activation of naive CD4+ and CD8+ T cells. J Immunol. 1999;162(6):3256-3262.

12. Schmidt CS, Mescher MF. Adjuvant effect of IL-12: conversion of peptide antigen administration from tolerizing to immunizing for CD8+ T cells in vivo. $J$ Immunol. 1999; 163(5):2561-2567.

13. Xiao Z, Casey KA, Jameson SC, Curtsinger JM, Mescher MF. Programming for CD8 T cell memory development requires IL-12 or type I IFN. J Immunol. 2009;182(5):2786-2794.

14. Agarwal P, et al. Gene regulation and chromatin remodeling by IL-12 and type I IFN in programming for CD8 T cell effector function and memory. JImmunol. 2009;183(3):1695-1704.

15. Trinchieri G. Interleukin-12 and the regulation of innate resistance and adaptive immunity. Nat Rev
Immunol. 2003;3(2):133-146.

16. Peterson AC, Harlin H, Gajewski TF. Immunization with Melan-A peptide-pulsed peripheral blood mononuclear cells plus recombinant human interleukin-12 induces clinical activity and T-cell responses in advanced melanoma. J Clin Oncol. 2003;21(12):2342-2348.

17. Hamid $\mathrm{O}$, et al. Alum with interleukin-12 augments immunity to a melanoma peptide vaccine: correlation with time to relapse in patients with resected high-risk disease. Clin Cancer Res. 2007;13(1):215-222.

18. Leonard JP, et al. Effects of single-dose interleukin-12 exposure on interleukin-12-associated toxicity and interferon-gamma production. Blood. 1997;90(7):2541-2548.

19. Atkins MB, et al. Phase I evaluation of intravenous recombinant human interleukin 12 in patients with advanced malignancies. Clin Cancer Res. 1997;3(3):409-417.

20. Kawakami Y, et al. Recognition of multiple epitopes in the human melanoma antigen gp 100 by tumor-infiltrating $\mathrm{T}$ lymphocytes associated with in vivo tumor regression. J Immunol. 1995;154(8):3961-3968.

21. Skipper JC, et al. Mass-spectrometric evaluation of HLA-A ${ }^{*} 0201$-associated peptides identifies dominant naturally processed forms of CTL epitopes from MART-1 and gp100. Int J Cancer. 1999;82(5):669-677.

22. Hayden $\mathrm{H}$, et al. Cryopreservation of monocytes is superior to cryopreservation of immature or semi-mature dendritic cells for dendritic cell-based immunotherapy. Jimmunother. 2009;32(6):638-654.

23. Walter S, et al. Multipeptide immune response to cancer vaccine IMA901 after single-dose cyclophosphamide associates with longer patient survival. Nat Med. 2012;18:1254-1261.

24. Therasse $P$, et al. New guidelines to evaluate the response to treatment in solid tumors. European Organization for Research and Treatment of Cancer, National Cancer Institute of the United States, National Cancer Institute of Canada. J Natl Cancer Inst. 2000;92(3)205-216.

25. Carreno BM, et al. Amino-terminal extended peptide single-chain trimers are potent synthetic agonists for memory human CD8+ T cells. J Immunol. 2012;188(12):5839-5849.

26. Carreno BM, Becker-Hapak M, Linette GP. CD40 regulates human dendritic cell-derived IL-7 production that, in turn, contributes to CD8(+) T-cell antigen-specific expansion. Immunol Cell Biol. 2009;87(2):167-177.

27. Snijders A, Hilkens CM, van der Pouw Kraan TC, Engel M, Aarden LA, Kapsenberg ML. Regulation of bioactive IL-12 production in lipopolysaccharide-stimulated human monocytes is determined by the expression of the p35 subunit. J Immunol.
1996;156(3):1207-1212

28. Napolitani G, Rinaldi A, Bertoni F, Sallusto F, Lanzavecchia A. Selected Toll-like receptor agonist combinations synergistically trigger a T helper type 1-polarizing program in dendritic cells. Nat Immunol. 2005;6(8):769-776.

29. Bohnenkamp HR, Papazisis KT, Burchell JM, Taylor-Papadimitriou J. Synergism of Toll-like receptor-induced interleukin- $12 \mathrm{p} 70$ secretion by monocyte-derived dendritic cells is mediated through p38 MAPK and lowers the threshold of T-helper cell type 1 responses. Cell Immunol. 2007;247(2):72-84.

30. Pufnock JS, et al. Priming CD8+ T cells with dendritic cells matured using TLR4 and TLR7/8 ligands together enhances generation of CD8+ T cells retaining CD28. Blood. 2011;117(24):6542-6551.

31. Cheever MA. Twelve immunotherapy drugs that could cure cancers. Immunol Rev. 2008;222:357-368.

32. Grover A, et al. Intralymphatic dendritic cell vaccination induces tumor antigen-specific, skin-homing $\mathrm{T}$ lymphocytes. Clin Cancer Res. 2006;12(19):5801-5808.

33. Barth RJ, et al. A randomized trial of ex vivo CD $40 \mathrm{~L}$ activation of a dendritic cell vaccine in colorectal cancer patients: tumor-specific immune responses are associated with improved survival. Clin Cancer Res. 2010;16(22):5548-5556.

34. Okada H, et al. Induction of CD8+ T-cell responses against novel glioma-associated antigen peptides and clinical activity by vaccinations with $\{$ alpha\}-type 1 polarized dendritic cells and polyinosinic-polycytidylic acid stabilized by lysine and carboxymethylcellulose in patients with recurrent malignant glioma. J Clin Oncol. 2011;29(3):330-336.

35. Hansen M, Met O, Svane IM, Andersen MH. Cellular based cancer vaccines: type 1 polarization of dendritic cells. Curr Med Chem. 2012;19(25):4239-4246.

36. Draube A, et al. Dendritic cell based tumor vaccination in prostate and renal cell cancer: a systematic review and meta-analysis. PLoS One. 2011;6(4):e18801.

37. Timmerman JM, et al. Idiotype-pulsed dendritic cell vaccination for B-cell lymphoma: clinical and immune responses in 35 patients. Blood. 2002;99(5):1517-1526.

38. Morse MA, Coleman RE, Akabani G, Niehaus N, Coleman D, Lyerly HK. Migration of human dendritic cells after injection in patients with metastatic malignancies. Cancer Res. 1999;59(1):56-58.

39. Nieda M, et al. Therapeutic activation of Valpha24+Vbeta11+ NKT cells in human subjects results in highly coordinated secondary activation of acquired and innate immunity. Blood. 2004;103(2):383-389.

40. Lesterhuis WJ, et al. Route of administration modulates the induction of dendritic cell vaccine-induced antigen-specific $\mathrm{T}$ cells in advanced melanoma patients. Clin Cancer Res. 2011;17(17):5725-5735. 
41. Bedrosian I, et al. Intranodal administration of peptide-pulsed mature dendritic cell vaccines results in superior CD8+ T-cell function in melanoma patients. J Clin Oncol. 2003;21(20):3826-3835.

42. Mantovani A, Sica A. Macrophages, innate immunity and cancer: balance, tolerance, and diversity. Curr Opin Immunol. 2010;22(2):231-237.

43. Gabrilovich DI, et al. Production of vascular endothelial growth factor by human tumors inhibits the functional maturation of dendritic cells. Nat Med. 1996;2(10):1096-1103.

44. Goriely S, et al. Deficient IL-12(p35) gene expression by dendritic cells derived from neonatal monocytes. J Immunol. 2001;166(3):2141-2146.

45. Goriely $\mathrm{S}$, et al. A defect in nucleosome remodeling prevents IL-12(p35) gene transcription in neonatal dendritic cells. J Exp Med. 2004;199(7):1011-1016.

46. Aksoy E, et al. Interferon regulatory factor 3-dependent responses to lipopolysaccharide are selectively blunted in cord blood cells. Blood. 2007;109(7):2887-2893.

47. Fridman WH, Pages F, Sautes-Fridman C, Galon $\mathrm{J}$. The immune contexture in human tumours: impact on clinical outcome. Nat Rev Cancer. 2012;12(4):298-306.

48. Minkis K, et al. Type 2 Bias of T cells expanded from the blood of melanoma patients switched to type 1 by IL-12p70 mRNA-transfected dendritic cells. Cancer Res. 2008;68(22):9441-9450.

49. Nevala WK, et al. Evidence of systemic Th2-driven chronic inflammation in patients with metastatic melanoma. Clin Cancer Res. 2009;15(6):1931-1939.

50. Tatsumi $\mathrm{T}$, et al. Disease-associated bias in $\mathrm{T}$ helper type 1 (Th1)/Th2 CD4(+) T cell responses against MAGE-6 in HLA-DRB10401(+) patients with renal cell carcinoma or melanoma. J Exp Med. 2002;196(5):619-628.

51. Rosenberg SA, et al. Immunologic and therapeutic evaluation of a synthetic peptide vaccine for the treatment of patients with metastatic melanoma. Nat Med. 1998;4(3):321-327.

52. Croft M, Carter L, Swain SL, Dutton RW. Generation of polarized antigen-specific CD8 effector populations: reciprocal action of interleukin (IL)-4 and IL-12 in promoting type 2 versus type 1 cytokine profiles. J Exp Med. 1994;180(5):1715-1728.

53. Macatonia SE, et al. Dendritic cells produce IL-12 and direct the development of Th1 cells from naive CD4+ T cells. J Immunol. 1995;154(10):5071-5079.

54. Schlom J. Therapeutic cancer vaccines: current status and moving forward. J Natl Cancer Inst. 2012;104(8):599-613.
55. Schuler G. Dendritic cells in cancer immunotherapy. Eur J Immunol. 2010;40(8):2123-2130.

56. Bhardwaj N. Harnessing the immune system to treat cancer. J Clin Invest. 2007;117(5):1130-1136.

57. Steinman RM, Banchereau J. Taking dendritic cells into medicine. Nature. 2007;449(7161):419-426.

58. Bacchetti P, Deeks SG, McCune JM. Breaking free of sample size dogma to perform innovative translational research. Sci Transl Med. 2011;3(87):87ps24.

59. Grupp SA, et al. Chimeric antigen receptor-modified T cells for acute lymphoid leukemia. $N$ Engl J Med. 2013;368(16):1509-1518.

60. Richter J, et al. Clinical regressions and broad immune activation following combination therapy targeting human NKT cells in myeloma. Blood. 2013;121(3):423-430.

61. Hoon DS, Foshag LJ, Nizze AS, Bohman R, Morton DL. Suppressor cell activity in a randomized trial of patients receiving active specific immunotherapy with melanoma cell vaccine and low dosages of cyclophosphamide. Cancer Res. 1990;50(17):5358-5364.

62. Linette GP, et al. Immunization using autologous dendritic cells pulsed with the melanomaassociated antigen gp100-derived G280-9V peptide elicits CD8+ immunity. Clin Cancer Res. 2005;11(21):7692-7699. 